\title{
PROFILE OF VISUAL IMPAIRMENT IN CHILDREN ATTENDING LOW VISION CLINIC OF NEPAL EYE HOSPITAL
}

\author{
Kishor Sapkota ${ }^{1}$, Sagar Rajkarnikar ${ }^{2}$, Bina Shrestha ${ }^{1}$, Shyam Panthi ${ }^{3}$, Archana Pokharel ${ }^{1}$ \\ ${ }^{1}$ Nepal Eye Hospital. ${ }^{2}$ Shree Birendra Hospital \\ ${ }^{3}$ BP Koirala Lions Centre of Ophthalmic Studies
}

\begin{abstract}
Introduction: Visual impairment (VI) in children accounts for great challenge in the life of children that leads to greater medical, psychological, social and economic problems since the child has to live up with handicap for many years to come. Identifying the main causes of visual degradation and their pattern will help in preventive measures, early diagnosis, treatment and rehabilitation of vulnerable population. The aim of this study was to find out the pattern of visual impairment in children attending low vision clinic of Nepal Eye Hospital.
\end{abstract}

Methods: A retrospective cross--sectional review of hospital records of all VI children attending the low vision clinic from $1^{\text {st }}$ May 2010 to $31^{\text {st }}$ April 2011 with age less than 16 years was done.

Results: Overall, 65 children were included in this study with mean age $11.58 \pm 3.83$ years. Among them $55.4 \%$ were male. More than one third (34\%) of the total children were in the category of blindness. More than two thirds (72.30\%) patients had refractive error. Majority of the patients (66.15\%) had multiple causes of visual impairment. Major causes of visual impairment were nystagmus (58.46\%), high refractive error (26.15\%) and amblyopia (24.61\%). Low vision devices were prescribed for only $18.46 \%$ of the total patients. Telescope was the most frequently prescribed low vision optical device.

Conclusion: Nystagmus, high refractive error and amblyopia were the main causes of VI. Most of the cases had multiple causes. Low vision devices were prescribed for very few of the visual impaired patients and telescope was the most frequently prescribed among them.

Key words: Nystagmus, Telescope, Visual impairment.

\section{INTRODUCTION}

Visual impairment (VI) is a condition where the best corrected visual acuity of a person is less than $6 / 18$ or the central visual field is less than or equal to 20 degrees in the better seeing-eye ${ }^{1}$. VI in childhood has lifelong adverse consequences for children and their families. Indeed, it affects the child's development, education and the care given by families and professionals, hence reducing the quality of life. ${ }^{2}$ Although visual impairment in children is less than the VI found in the adult group; ${ }^{3}$ the number of blind years experienced by these children in their whole life is longer, thus very significant. VI creates serious medical, psychological, social and economical problems.

In Nepal, it is estimated that $0.86 \%$ of the children have VI. ${ }^{4}$ Many children with low vision go to the school

\section{Correspondence:}

Mr. Kishor Sapkota

Nepal Eye Hospital

Email: kishorsapkota@gmail.com, kishorsapkotahotmail.com

Cell No.: 9841475300 
for blind in Nepal ${ }^{5}$ because of lack of proper low vision rehabilitation services. They have to use Braille in spite of having some amount of vision; even though they can perform their daily living activities in a normal way by using suitable low vision device and simple modification of working environment. Visual acuity and the reading speed of the visually impaired children can be improved by low vision devices and their training. ${ }^{6,7}$ Thus quality of life of the visually impaired children gets better by low vision devices. However prescription of low vision devices depends upon the individuals. ${ }^{8}$

Studies done in different parts of the world show that more than half of the visual impairments are due to either avoidable ${ }^{9,10}$ or preventable causes. ${ }^{5,11}$ This study was done to find out the major causes of visual impairment in children attending Nepal Eye Hospital, their visual status and low vision devices prescribed. The study will be helpful in the improvement of preventive measures, early diagnosis, treatment and low vision rehabilitation of such children.

\section{METHODS}

A retrospective analysis of the patients' records of low vision clinic of Nepal Eye Hospital, Kathmandu was done. All the low vision patients attending low vision clinic from $1^{\text {st }}$ May 2010 to $31^{\text {st }}$ April 2011 for the first time with age less than 16 years were included. Patients with vision better than $6 / 18$ in the better seeing eye were excluded.

Visual acuity was taken for each eye separately and together with the correction if present by using Baily Lovie chart with $100 \%$ contrast at a distance of 3 meter. Cycloplegic refraction was done for each individual and the best corrective glasses were prescribed. Ocular examination was done with slit lamp biomicroscope and direct ophthalmoscope on dilated pupil. After recovering from the cycloplegic effect, the patients' distance and near vision was reassessed with proper optical device. Most suitable optical devices were prescribed.

SPSS 13 was used for the analysis of the data. P value less than 0.05 was considered as statistically significantly.

\section{RESULTS}

There were 65 children with visual impairment out of which $55.4 \%$ (36) were boys and $44.6 \%$ (29) were girls. Statistically, there was not significant difference in the gender (Nonparametric Binomial test, $p=0.457$ ). The mean age was 11.58 years with standard deviation \pm 3.83 ranging from 4-17 years.

Thirty four percent (22) children were with moderate visual impairment and same number of the children had blindness. Remaining 32\% were severe visual impairmed.
Most of the children (72.30\%) were having refractive error. There were 20 myopic children (11 male and 9 female) with mean spherical equivalent power of $-3.92 \mathrm{D} \pm 4.14 \mathrm{D}$ (range $-0.38 \mathrm{D}$ to $-18.00 \mathrm{D}$ ). There were 27 hyperopic patients ( 13 male and 14 female) with mean spherical equivalent power of $+5.56 \mathrm{D} \pm 3.99 \mathrm{D}$. Eighteen children (12 male, 6 female) had no refractive error.

96.9\% (63) children had at least one cause behind the degradation of vision while two cases were iatrogenic. Out of them, 20 have single cause, 23 had two causes, 17 had three causes and 3 had four causes of visual impairment. Thus most of the patients $(43,66.15 \%)$ had multiple causes of visual impairment. The mean of the number of causes of visual impairment was $1.98 \pm 0.94$.

Nystagmus. was the most common cause of visual impairment comprising $(58.46 \%)$ of the total visual impaired children. High refractive error (26.15\%), amblyopia (24.61\%), cataract (16.92\%), microophthalmus (12.31\%) and retinal or choroidal coloboma (10.77\%) were the other major causes of visual impairment in this study population. Figure 1.

Conventional spectacles were prescribed for 40 (61.53\%) children. At least one form of optical low vision device was prescribed for 12 (18.46\%) of them. Out of them, single optical device was prescribed for $8(12.31 \%)$ children and two types of devices were prescribed for 4 (6.15\%) patients. Telescope was prescribed for 10 (15.38\%), hand held magnifier for 4 (7.69\%) and stand magnifier for 1 patient.

\section{Table 1. Demographic data.}

\begin{tabular}{cc}
\hline Sex of the patients & \\
Male & $36(55.4 \%)$ \\
Female & $29(44.6 \%)$ \\
Degree of visual impairement & \\
Moderate visual impairement & $34 \%$ \\
Severe visual impairement & $32 \%$ \\
Blindness & $34 \%$ \\
\hline
\end{tabular}

Figure 1. Causes of visual impairment

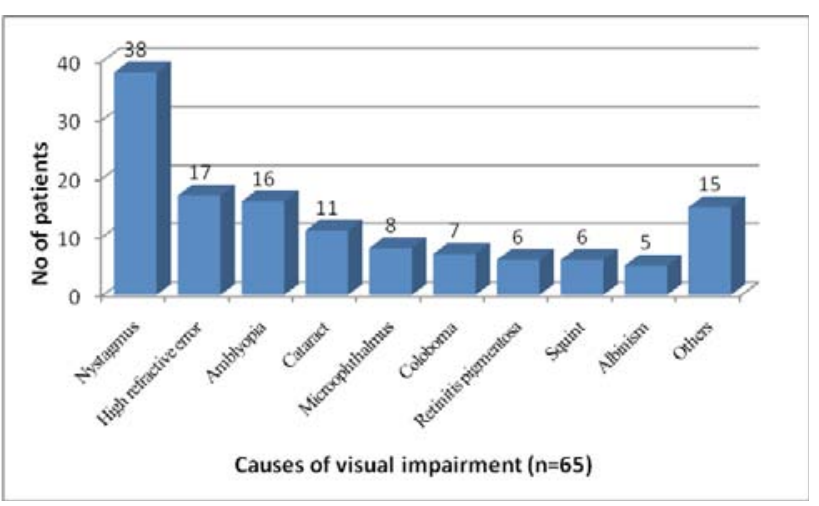




\section{DISCUSSION}

In our study, the number of boys with VI was slightly higher than that of girls but there was not statistically significant difference. Similar results were found in other studies $^{10,12,13}$ too.

In our study population, $34 \%$ children had moderate visual impairment, $34 \%$ had blindness and $32 \%$ had severe visual impairment. Similar results were obtained in the Haddad et al study ${ }^{13}$.

Almost two thirds (66.15\%) of the participants had multiple causes of visual impairment. In an average, each child had two causes behind the vision impairment. Nystagmus, the major cause of visual impairement in this group, was found in more than half of the participants. High refractive error and the amblyopia were the second and the third common causes respectively. These findings were quite different to the outcomes of the other studies performed in other parts of the world. In a study ${ }^{14}$ done in Chinese children the main causes of visual impairment were cataract $(24.4 \%)$, retinal dystrophy $(10.7 \%)$ and optic nerve hypoplasia (8.4\%). Similarly in an Indian study ${ }^{12}$ strabismus, nystagmus and optic atrophy were the most common causes of visual impairment. Similarly, congenital glaucoma, hereditary macular degeneration, retinitis pigmentosa and albinism were found as the major four causes of visual impairment in a survey performed in another Indian population. ${ }^{15}$ In a multi-continent survey performed by Gilbert et al, ${ }^{16}$ retinal lesion and amblyopia were the commonest causes of visual impairment. In Pakistani children, the major causes of visual impairment found were nystagmus (15\%), Stargardt's disease (14\%), maculopathy (13\%), myopic macular degeneration (11\%) and oculocutaneous albinism (7\%). ${ }^{17}$

Conventional spectacles were most commonly prescribed in our study population as found in other studies. ${ }^{12,17}$ However, low vision devices were prescribed for less than one fifth of these children. Telescope was the most frequently prescribed low vision aid. Our study revealed that very few visual impaired children were prescribed low vision devices in comparison to other studies. In studies done by van Rens et $\mathrm{al}^{18}$ in the Netherlands and Temel $A^{19}$ in Turkey, they found that low vision devices were prescribed for $79.7 \%$ and $77 \%$ of the total participants respectively. However, the participants of these studies were adult group. In an another study done by Haddad et $\mathrm{al}^{13} 52.9 \%$ of the visual impaired children were prescribed at least one type of low vision aids. In their study, telescopic system was prescribed for $26.8 \%$ chidren and magnifying bar was prescribed for $33.3 \%$ children.

\section{CONCLUSION}

Most of the children with visual impairment were ametropic. Two thirds of the patients had multiple causes of visual degradation. Nystagmus, high refractive error and the amblyopia were the major causes of visual impairment. Although conventional types of glasses were prescribed to majority of patients, low vision devices were prescribed to less than one fifth of these children. Proper referral system of the visual impaired children and encouragement of using low vision devices for the children as well as frequent monitoring of the use of low vision devices is necessary for the improvement of the lifestyle of visual impaired children.

\section{REFERENCES}

1. World Health Organization (1992) International Statistical Classification of Diseases and Related Health Problems. Vol. 1. 10th rev. Geneva: World Health Organization.

2. Chadha RK, Subramanian A. The effect of visual impairment on quality of life of children aged 3 e16 years. Br J Ophthalmol 2011;95:642-645.

3. Charles N. Estimates of the number of older people with a visual impairment in the UK. Br J Vis Impair 2007;25:199-215.

4. Sapkota YD, Adhikari BN, Pokharel GP, Poudyal BK, Ellwein LB. The prevalence of visual impairment in school children of upper-middle socioeconomic status in Kathmandu. Ophthalmic Epidemiol. 2008;15(1):17-23.

5. Kansakar I, Thapa HB, Salma KC, Ganguly S, Kandel RP, Rajasekaran S. Causes of vision impairment and assessment of need for low vision services for students of blind schools in Nepal. Kathmandu Univ Med J (KUMJ). 2009;7(25):44-9.

6. Pearce $E$, Crossland MD, Rubin GS. The efficacy of low vision device training in a hospital-based low vision clinic. $\mathrm{Br} J$ Ophthalmol 2011;95:105e108.

7. Nguyen NX, Weismann M, Trauzettel-Klosinski S. Improvement of reading speed after providing of low vision aids in patients with age-related macular degeneration. Acta Ophthalmol. 2009;87(8):849-53.

8. Gajdosová E, Kukurová E, Gerinec A. [Improvement in the outcome of visual impairment using low vision aids in children]. Cesk Slov Oftalmol. 2010;66(6):266-72.

9. Muecke J, Hammerton M, Aung YY, Warrier S, Kong A, Morse A, Holmes M, Yapp M, Hamilton C, Selva D. A survey of visual impairment and blindness in children attending seven schools for the blind in Myanmar. Ophthalmic Epidemiol. 2009;16(6):370-7.

10. Muhit MA, Shah SP, Gilbert CE, Foster A. Causes of severe visual impairment and blindness in Bangladesh: a study of 1935 children. Br J Ophthalmol 2007;91:1000-1004. 
11. Kocur I, Kuchynka P, Rodny S', Baráková D, Schwartz E C Causes of severe visual impairment and blindness in children attending schools for the visually handicapped in the Czech Republic. Br J Ophthalmol 2001;85:1149-1152.

12. Gogate P, Soneji FR, Kharat J, Dulera H, Deshpande M, Gilbert C. Ocular disorders in children with learning disabilities in special education schools of Pune, India. Indian J Ophthalmol. 2011;59(3):223-8.

13. Haddad MA, Lobato FJ, Sampaio MW, Kara-José N. Pediatric and adolescent population with visual impairment: study of 385 cases. Clinics (Sao Paulo). 2006;61(3):239-46.

14. Shi $Y, X u Z$. [An investigation on causes of blindness of children in seven blind schools in East China]. Zhonghua Yan Ke Za Zhi. 2002;38(12):747-9.

15. Gothwal VK, Herse P. Characteristics of a paediatric low vision population in a private eye hospital in India. Ophthalmic Physiol Opt. 2000;20(3):212-9.
16. Gilbert CE, Ellwein LB; Refractive Error Study in Children Study Group. Prevalence and causes of functional low vision in school-age children: results from standardized population surveys in Asia, Africa, and Latin America. Invest Ophthalmol Vis Sci. 2008;49(3):877-81.

17. Shah M, Khan M, Khan MT, Khan MY, Saeed N. Causes of visual impairment in children with low vision. J Coll Physicians Surg Pak. 2011;21(2):88-92.

18. Van Rens GH, Chmielowski RJ, Lemmens WA. Results obtained with low vision aids. A retrospective study. Doc Ophthalmol. 1991;78(3-4):205-10.

19. Temel A. Low vision aids (evaluation of 185 patients). Ophthalmic Physiol Opt. 1989;9(3):327-31. 